\title{
Stability and Performance Assessment in 18 Short-Duration Rice Genotypes under Rain Fed Lowland Production Conditions of Ethiopia
}

\author{
*Taddesse Lakew ${ }^{1} \quad$ Abebaw Dessie $^{1} \quad$ Betelhem Asrat $^{1} \quad$ Asaye Berie $^{1} \quad$ Atsedemariam Tewachew $^{1}$ \\ Desta Abebe $^{2} \quad$ Hailemariam Solomon ${ }^{3}$ \\ 1.Ethiopian Institute of Agricultural Research, Fogera Rice Research and Training Center, Ethiopia \\ 2.Ethiopian Institute of Agricultural Research, Pawe Agricultural Research Centre, Pawe, Ethiopia \\ 3.Ethiopian Institute of Agricultural Research, Melkassa Agricultural Research Centre, Melkassa, Ethiopia
}

\begin{abstract}
In order to identify high yielding and stable short-duration lowland rice genotypes, field experiment was conducted with 18 rice genotypes for three consecutive years (2013-2015) at five locations in a randomized complete block design of three replications. Combined analysis of variance showed highly significant differences for the genotype and environments. The genotype by environment interaction (GEI) was also highly significant indicating differential response of genotypes to environments. The partitioning of total sum of squares exhibited that the GEI effect was a predominant source of variation $(34.44 \%)$, followed by the environment and genotype effects of $24.3 \%$ and $19.04 \%$, respectively. The GEI effect was nearly two times higher than that of the genotype effect, suggesting the presence of different environment groups. In the AMMI analysis, the first six interaction principal component axes (IPCA1 to IPCA6) were highly significant and together explained 92.18\% of interaction sum of squares. AMMI stability value (ASV) discriminated genotypes G17, G16 and G8 as the stable genotypes. But, based on the yield stability index (YSI), the most stable genotypes with high grain yield were genotypes G16 and G11. AMMI1 and GGE biplots also recommended G16 and G11as stable and high yielding genotypes, whereas G2 as unstable but high yielding. Thus, genotypes G16 and G11could be released for wider adaptation while genotype $\mathrm{G} 2$ for specific adaptation.
\end{abstract}

Keywords: Lowland rice, AMMI, GGE, AMMI stability value, yield stability index.

DOI: $10.7176 / \mathrm{JEES} / 11-7-02$

Publication date:July $31^{\text {st }} 2021$

\section{Introduction}

Rice is the world's second most important cereal crop next to wheat in terms of total production and after maize in terms of area coverage and productivity (FAOSTAT, 2020). The crop is grown worldwide over an area of 163.24 Mha with a total production of around $740.95 \mathrm{Mt}$ and world average productivity of $4.66 \mathrm{t} \mathrm{ha}^{-}$ ${ }^{1}$ (FAOSTAT, 2020). Globally, human consumption accounts for $85 \%$ of total production for rice, compared with $72 \%$ for wheat and $19 \%$ for maize and rice crop also provides $21 \%$ of global human per capita energy and $15 \%$ of per capita protein (Maclean et al., 2002). Rice has also become a commodity of strategic significance and the fastest growing food source in Africa. Its adoption as a principal staple food is increasing and is grown and consumed in more than 43 African countries (AfricaRice, 2017), and yet domestic production never meet local rice demand leading to huge annual import. In Ethiopia, rice is an increasingly important food, feed and cash crop and, it is also source of employment for the youth and women as well as other actors involved along the rice value chain. Despite its economic and food security importance, productivity of the crop is constrained by several factors such as terminal moisture stress, cold stress, low soil fertility, blast and sheath rot, among other things. Terminal moisture stress is predominantly a common problem in lowland rain fed rice cultivation. High yielding rice varieties with short growing duration are required to sustain rain fed lowland rice production in Ethiopia. To this end, introduction and screening of different rice genotype through multi-environment evaluation has been practiced under rice variety improvement program.

Multi-environment trials are conducted to evaluate yield stability performance of plant materials in diverse environmental conditions (Yan et al., 2000; Yan and Rajcan, 2002). Genotypes grown in different environments often show significant fluctuations of performance for yield and yield related traits. These changes are influenced by the different environmental conditions such as variations in moisture, soil nutrients, temperature and relative humidity, and this is referred to as genotype-by-environment (GE) interaction (Kang, 2002). The GE interaction reduces the association between phenotypic and genotypic values and leads to bias in the estimates of gene effects and combining ability for various characters that are sensitive to environmental fluctuations less amenable to selection (Farshadfar et al., 2000; Kang, 2002). Hence, GE interaction must be either exploited by selecting best genotype for each specific environment or avoided by selecting widely adapted and stable genotype across a wide range of environments (Eisemann et al., 1990; Kang, 2002).

Although different methods have been reported by scholars to understand pattern of GE interaction in multi- 
environment data, the two most often used statistical models are additive main effects and multiplicative interaction (AMMI) as reported by Gauch and Zobel (1988) and Zobel et al. (1988), and genotype plus GE interaction (GGE) based on Yan et al. (2000). The AMMI analysis combines analysis of variance for genotype and environment main effects with principal components analysis of the $\mathrm{G} \times \mathrm{E}$ interaction into a unified approach (Gauch, 1988; Zobel et al., 1988) while the GGE biplot as a data visualization tool is able to graphically demonstrate GE interaction patterns. GGE biplot is an effective tool to rank genotypes based on mean yield and stability and to identify mega-environments with corresponding winner genotypes as well as to evaluate test environments. Therefore, the objective of the current study was to identify high yielding shortduration lowland rice genotypes with wider or specific adaptation by applying AMMI and GGE statistical tools.

\section{Materials and Methods}

\subsection{Plant materials, experimental design and trial management}

In this study, including one check (Ediget), a total of 18 lowland rice genotypes were used and evaluated for grain yield and yield related traits (Table 1). The experiment was laid out using a randomized complete block design (RCBD) of three replications. Seeds of each genotype were hand drilled at the rate of $60 \mathrm{kgha}^{-1}$ in a plot size of $6 \mathrm{~m}^{2}$ and with a spacing of $20 \mathrm{~cm}$ between rows. Each experimental plot comprised six rows of the gross plot, with only four harvestable rows. Fertilizers (UREA and DAP) were applied as per to local recommendations. The DAP was applied all at planting while UREA was applied in three splits-at sowing, tillering, and panicle initiation. Other crop management practices were applied to the entire experimental area uniformly.

\subsection{Experimental sites}

This experiment was executed at Woreta, Pawe, Assosa, Mai-Tsebri, and Jimma research stations from 2013 to 2015 during the main cropping seasons under rain fed lowland conditions. As presented in Table 2, experimental sites are different in terms of rainfall amount and distribution, elevation, and temperature. The location-year combination produced eleven environments including E1: Woreta 2013, E2: Maitsebri 2013, E3: Jimma 2013, E4: Woreta 2014, E5: Jimma 2014, E6: Maitsebri 2014, E7: Pawe 2014, E8: Woreta 2015, E9: Pawe2015, E10: Jimma 2015, and E11: Assosa 2015.

Table 1. Description of 18 rice genotypes evaluated at eleven environments over three years

\begin{tabular}{llc}
\hline No. & Genotypes & Code \\
\hline 1 & IR74052-184-3-3 & $\mathrm{G} 1$ \\
2 & YUNJING 23 & $\mathrm{G} 2$ \\
3 & WAB502-8-5-1 & $\mathrm{G} 3$ \\
4 & PSBRC44 & $\mathrm{G} 4$ \\
5 & WAB376-B-10-H3 & $\mathrm{G} 5$ \\
6 & IR 83222-F11-167 & $\mathrm{G} 6$ \\
7 & IR 83222-F11-18 & $\mathrm{G} 7$ \\
8 & IR 83222-F11-200 & $\mathrm{G} 8$ \\
9 & IR 83222-F11-209 & $\mathrm{G} 9$ \\
10 & IR 83222-F11-66 & $\mathrm{G} 10$ \\
11 & IR76999-52-1-3-2 & $\mathrm{G} 11$ \\
12 & IR 83249-F9-29 & $\mathrm{G} 12$ \\
13 & STEJAREE 45 & $\mathrm{G} 13$ \\
14 & CHOMRONG & $\mathrm{G} 14$ \\
15 & WAB880-1-38-20-17-P1-HB & $\mathrm{G} 15$ \\
16 & WAB880-1-32-1-2-P1-HB & $\mathrm{G} 16$ \\
17 & IRAT112 & $\mathrm{G} 17$ \\
\hline
\end{tabular}

Table 2. Description of the test locations in Ethiopia over three years

\begin{tabular}{|c|c|c|c|c|c|c|}
\hline \multirow[t]{2}{*}{ Location } & \multicolumn{2}{|c|}{ Coordinates } & \multirow{2}{*}{$\begin{array}{c}\text { Elevation }^{\mathrm{a}} \\
\text { (masl) }\end{array}$} & \multirow{2}{*}{$\begin{array}{c}\text { Rain fall }^{b} \\
(\mathbf{m m})\end{array}$} & \multicolumn{2}{|c|}{ Temperature $\left({ }^{\circ} \mathrm{C}\right)^{\mathrm{c}}$} \\
\hline & Latitude & longitude & & & Min. & Max. \\
\hline Woreta & $11^{\circ} 58^{\prime} \mathrm{N}$ & $37^{\circ} 41^{\prime} \mathrm{E}$ & 1810 & 1300 & 11.5 & 27.9 \\
\hline Jimma & $7^{\circ} 46^{\prime} \mathrm{N}$ & $36^{\circ} 00^{\prime} \mathrm{E}$ & 1753 & 1561 & 11.2 & 25.9 \\
\hline Maitsebri & $11^{\circ} 08^{\prime} \mathrm{N}$ & $38^{\circ} 08^{\prime} \mathrm{E}$ & 1350 & 1296 & 15.0 & 36.0 \\
\hline Pawe & $11^{\circ} 19^{\prime} 15^{\prime \prime} \mathrm{N}$ & $36^{\circ} 24^{\prime} 30^{\prime \prime} \mathrm{E}$ & 1091 & 1457 & 17.2 & 32.8 \\
\hline Assosa & $10^{\circ} 03^{\prime} \mathrm{N}$ & $34^{\circ} 59^{\prime} \mathrm{E}$ & 1590 & 1050 & 14.0 & 29.0 \\
\hline
\end{tabular}

\footnotetext{
${ }^{\mathrm{a}}$ masl: meter above sea level, ${ }^{\mathrm{b}} \mathrm{mm}$ : millimeter, ${ }^{\mathrm{c}}$ Min: minimum and Max: maximum
} 


\subsection{Data collection and statistical analysis}

Data were collected for days to heading (DTH), days to maturity (DTM), panicle length (PL), plant height (PH), number of filled grains per panicle (FSP), fertility rate (FR), grain yield (Gy), thousand seed weight (TSW) and disease data such as leaf blast (LB) and brown spot (BS) were collected based on 0-9 scale following IRRI standard evaluation system (IRRI, 1996); where 0: immune, 1:highly resistant, 2: resistant, 3 and 4: moderately resistant, 5 and 6: moderately susceptible, 7: susceptible, and 8 and 9: highly susceptible. Grain yield harvested from each plot was converted into $\mathrm{kgha}^{-1}$ at $14 \%$ standard grain moisture content. Data were subjected to analysis of variance using the General Linear Model (PROC GLM) of the SAS Procedure version 9.0 of the SAS software (SAS, 2002) to determine significant variation among genotypes and environments and their interaction. Mean performance of different traits were separated using Least Significant Difference (LSD) method at 0.05 level of probability. Additive main effects and multiplicative interaction (AMMI) model was applied to assess the effect of genotype by environment interaction, and stability of rice genotypes (Zobel et al., 1988) using GenStat $\left(16^{\text {th }}\right.$ edition) statistical package. Moreover, GGE analysis, according to Yan et al. (2000), was employed to visualize grain yield stability and performance, and identify specifically adapted genotypes among 18 rice genotypes at eleven environments. In this study, AMMI stability value (ASV) was estimated for each genotype according to the relative contributions of the principal component axis scores (IPCA1 and IPCA2) to the interaction sum of squares according to Purchase et al. (2000) as described below:

$\mathrm{ASV}=\sqrt{\left[\frac{\text { SSIPCA1 }}{\text { SSIPCA2 }} \text { (IPCA1Score) }\right] 2+\text { (IPCA2Score) } 2}$,

Where, $\mathrm{ASV}=\mathrm{AMMI}$ stability value; $\mathrm{SS}=$ sum of square; IPCA1 and IPCA2= the first and the second interaction principal component axes, respectively. The larger the IPCA score is, either

negative or positive, the more adapted a genotype is to a certain environment. Smaller ASV scores indicate a more stable genotype across environments (Farshadfar et al., 2011). Yield stability index (YSI) was also estimated using the sum of the ranking based on yield and ranking based on the AMMI stability value i.e YSI= RASV+RY, where RASV is the rank of the genotypes based on the AMMI stability value; RY is the rank of the genotypes based on yield across environments. YSI incorporates both mean yield and stability in a single criterion (Tumuhimbise et al., 2014; Bose et al., 2014) and low values of YSI show desirable genotypes with high mean grain yield and stability.

\section{Results and discussions}

\subsection{Variation in traits}

The combined analysis of variance over locations and years of all traits, and the AMMI analysis of variance for grain yield are presented in Table 3 and Table 4, respectively. Means squares of genotype (G), location (L), and year $(\mathrm{Y})$ showed highly significant variation for all traits considered except for filled grains per panicle in the case of year effect (Table 3). Two-way interactions of all combinations and the three-way interactions ( $\mathrm{G} \mathrm{x} \mathrm{L} \mathrm{x}$ $\mathrm{Y})$ (except for fertile tillers) showed significant variation for all traits revealing the inconsistence performance of genotypes for different traits across locations and over the years. Similar results were reported by Hasan et al. (2014), Ogunbayo et al. (2014) and Bose et al. (2014) for rice genotypes performance across sites and over seasons. The result in AMMI analysis of variance for grain yield revealed that environment (E), genotype $(\mathrm{G})$ and genotype by environment $(\mathrm{GE})$ interaction were highly significant $(\mathrm{P}<0.001)$. In multi-environment trial data, the largest variation in grain yield is attributed to $\mathrm{E}$, followed by GE interaction and then by G (Gauch, 2006; Yan and Kang, 2003).

Table 3. Mean squares of grain yield and yield related traits in 18 lowland rice genotypes at five locations for three years

\begin{tabular}{|c|c|c|c|c|c|c|c|c|c|c|}
\hline \multirow{2}{*}{$\begin{array}{ll}\text { Source } \\
\text { variation }\end{array}$} & \multirow{2}{*}{$\begin{array}{c}\text { Degree } \\
\text { of } \\
\text { freedom }\end{array}$} & \multicolumn{9}{|c|}{ Traits $^{\mathrm{a}}$} \\
\hline & & Gy & DTH & DTM & PL & PH & FTP & FSP & FR & TSW \\
\hline Genotype (G) & 17 & $13071394.2^{* * *}$ & $2290 * * *$ & $544 * * *$ & $59.1 * * *$ & $7325.1 * * *$ & $17.9^{* * *}$ & $3049.4^{* * *}$ & $366.1 * * *$ & $346.1 * * *$ \\
\hline Year (Y) & 2 & $4992248.8^{* *}$ & $3778 * * *$ & $13767 * * *$ & $45.4^{* * *}$ & $1452.3^{* * *}$ & $740.9 * * *$ & $474.9 \mathrm{~ns}$ & $1786.0^{* * *}$ & $127.1 * * *$ \\
\hline Location (L) & 4 & $24775165.1 * * *$ & $2297 * * *$ & $13540 * * *$ & $179.9 * * *$ & $2374.9 * * *$ & $544.9 * * *$ & $5510.1 * * *$ & $6526.4 * * *$ & $252.5 * * *$ \\
\hline $\mathrm{G}^{*} \mathrm{Y}$ & 34 & $1881240.2 * * *$ & $44 * * *$ & $61 * *$ & $4.2 * *$ & $187.5 * *$ & $4.9^{*}$ & $593.2 * * *$ & $93.2 * * *$ & $9.9^{*}$ \\
\hline $\mathrm{G}^{*} \mathrm{~L}$ & 68 & $3016525.5^{* * *}$ & $29 * * *$ & $66 * *$ & $5.3 * * *$ & $118.3^{* *}$ & $4.9^{* *}$ & $416.6^{* * * *}$ & $91.5^{* * *}$ & $8.5^{*}$ \\
\hline $\mathrm{Y}^{*} \mathrm{~L}$ & 4 & $43630073.7^{* * *}$ & $899 * * *$ & $5006^{* *}$ & $83.3 * * *$ & $2853.5^{* *}$ & $358.2 * * *$ & $9993.6^{* * * *}$ & $590.9 * * *$ & $181.1 * * *$ \\
\hline $\mathrm{G}^{*} \mathrm{Y}^{*} \mathrm{~L}$ & 68 & $1953553.4 * * *$ & $33 * * *$ & $26^{* *}$ & $3.3^{*}$ & $71.5^{* *}$ & $3.7 \mathrm{~ns}$ & $665.9^{* * *}$ & $76.1 * * *$ & $9.5^{* *}$ \\
\hline Error & 394 & 657018 & 14.7 & 10.8 & 2.3 & 34.4 & 3.2 & 198 & 25.3 & 6.2 \\
\hline
\end{tabular}

${ }^{\mathrm{a}}$ Gy: grain yield $\left(\mathrm{kgha}^{-1}\right)$, DTH: days to heading, DTM: days to maturity, PL: panicle length $(\mathrm{cm})$, PL: plant height (cm), FSP: number of filled grains per panicle (no), FR: fertility rate (\%) and TSW: thousand seed weight (g). 
Table 4. AMMI analysis of variance for grain yield in 18 lowland rice genotypes at eleven environments

\begin{tabular}{|c|c|c|c|c|c|c|}
\hline $\begin{array}{l}\text { Source of } \\
\text { Variation }\end{array}$ & Degree of freedom & $\begin{array}{l}\text { Sum of squarer } \\
\text { (SS) }\end{array}$ & $\begin{array}{l}\text { Mean Square } \\
\text { (MS) }\end{array}$ & $\begin{array}{l}\text { \%total } \\
\text { SS }\end{array}$ & $\begin{array}{c}\text { \%treatment } \\
\text { SS }\end{array}$ & $\begin{array}{c}\text { \%GxE } \\
\text { SS }\end{array}$ \\
\hline Total & 593 & 1167179964 & 1968263 & & & \\
\hline Treatments & 197 & 907769374 & $4607966^{* * *}$ & & & \\
\hline Genotypes (G) & 17 & 222217166 & $13071598 * * *$ & 19.04 & 24.48 & \\
\hline Environments (E) & 10 & 283600326 & $28360033 * * *$ & 24.30 & 31.24 & \\
\hline Block & 22 & 26612553 & $1209661 * *$ & & & \\
\hline Gx E & 170 & 401951882 & $2364423 * * *$ & 34.44 & 44.28 & \\
\hline IPCA 1 & 26 & 112365614 & $4321754 * * *$ & & & 27.95 \\
\hline IPCA 2 & 24 & 90592511 & $3774688 * * *$ & & & 22.54 \\
\hline IPCA 3 & 22 & 67005829 & $3045720 * * *$ & & & 16.67 \\
\hline IPCA 4 & 20 & 36963500 & $1848175 * * *$ & & & 9.20 \\
\hline IPCA 5 & 18 & 33681278 & $1871182 * * *$ & & & 8.38 \\
\hline IPCA 6 & 16 & 29918616 & $1869913 * * *$ & & & 7.44 \\
\hline Residuals & 18 & 7971605 & 442867 & & & 1.98 \\
\hline Error & 374 & 232798038 & 622455 & 19.95 & & \\
\hline
\end{tabular}

DF: degree of freedom, SS: sum of squares, MS: mean squares

In this study, however, grain yield was largely influenced by GE interaction effect $(34.4 \%)$, followed by $\mathrm{E}$ $(24.3 \%)$ and $\mathrm{G}(\sim 19 \%)$ effects which is in agreement with the findings Cantila et al. (2020) who reported that GE interaction, $\mathrm{E}$, and $\mathrm{G}$ explained $52.3 \%, 26.8 \%$, and $15.5 \%$ of the total variation. Treatment sum of square was also largely explained by GE interaction (44.3\%), followed by E ( 31.2\%) and G ( 24.5\%) (Table 4). The variation attributed to GE interaction was nearly twice that of the genotype effect.

As reported by Yan and Kang (2003), the large GE interaction effect relative to genotype implies that environments might be divided into mega-environments to which genotypes responded differently. In this study it was also observed that the first six highly significant IPCAs (IPCA1 to IPCA6) together explained 92.2\% of the total GE interaction effect, with each accounting for $28,22.5,16.7,9.2,8.4$ and $7.4 \%$ of GE interaction, respectively (Table 4). However, Cantila et al. (2020) reported that the first four highly significant IPCAs explained $35.8 \%, 26.9 \%, 16.9 \%$ and $13.4 \%$ of GE interaction sum of squares while Taddesse et al. (2017) reported that the first three significant IPCAs explained 35.6, 27.1 and 18.8\% of the total GE interaction sum of squares, respectively.

\subsection{Mean performance of rice genotypes}

The mean values of growth and yield traits of 16 lowland rice genotypes (days to $50 \%$ heading, days to $85 \%$ maturity, panicle length, plant height, filled grains per panicle, fertility rate, thousand seed weight, and grain yield) combined across eleven environments are presented in Table 5. In days to 50\% heading and days to $85 \%$ maturity, nearly $44 \%$ of the genotypes had days to heading and days to maturity higher than the grand mean. The least days to heading was observed in three genotypes; G8 (72 days), G14 (71 days and G16 (72 days) which was slightly lower than the standard check, G18 (73 days), while only one genotype (G14) was earlier than the standard check in terms of days to maturity. In the case of panicle length, genotypes G1, G3, G4, G5, G11, G14, G15 and G16 exhibited the longest panicle length and slightly longer than the standard check and about 50\% of genotypes showed the tallest plant height, measuring 90 to $114 \mathrm{~cm}$ which was higher than the grand mean, but G9, G7, G3, and G11 were significantly shorter than the standard check, measuring 71 to $74.6 \mathrm{~cm}$. The total number of filled grains per panicle was the highest in G10, followed by G12, G17, G4, G16, G2 and G18 which was higher than the grand mean and they also had high grain fertility rate. Thousand seed weight was the highest in G16 (32.8 g) and G18 (32.8g), followed by G13 (31.4g), G15 (G31.3g), G14 (30.4g) and G17 (30.2g) with overall mean of $28.02 \mathrm{~g}$. Mean grain yield of genotypes also ranged from the lowest of $3439.1 \mathrm{kgha}^{-1}$ for G13 to the highest of $5812.3 \mathrm{kgha}^{-1}$ for G16 with grand mean of $4561 \mathrm{kgha}^{-1}$. Only three genotypes (G2, G11 and G16) significantly outperformed the standard check (G18) with mean grain yield of 5409.8, 5423.1 and $5812.3 \mathrm{kgha}^{-1}$, respectively (Table 5). These high yielding genotypes also showed better resistance to major rice diseases (panicle blast and brown spot) compared to the other genotypes.

As presented in Table 6, genotypes responded differently across eleven environments. The mean grain yield across genotypes in terms of environments ranged from $3741 \mathrm{~kg} \mathrm{ha}^{-1}$ at E1 to $5828 \mathrm{~kg} \mathrm{ha}^{-1}$ at E4, with grand mean of $4561 \mathrm{~kg} \mathrm{ha}^{-1}$. E2, E4 and E E11 were high yielding environments, followed by E8 and E9 while E1 was the lowest yielding environment (Table 6). This low performance of genotypes at E1 might be attributed to the poor environmental conditions, mainly of moisture stress and the condition became better in the following years. As reported by Tilahun et al. (2013) and Lakew et al. (2021) Fogera plains (Woreta, Dera and Libokemkem) are characterized by moisture stress (late-on set and early off-set of rainfall) which often negatively impacted yield performance of lowland rice. Short growth duration rice varieties are preferred by farmers in these areas which 
help escape moisture stress and encourage double cropping thereby increasing productivity of their fields. Genotypes G7, G12 and G16 performed the best at the lowest yielding environment (E1), whereas G2, G11, and G14 had the highest mean grain yield at the most favorable environment (E4). Except for genotypes G6, G8, G9, G13, G17, and G18, each of the other genotypes were identified as one of the three high yielding genotypes at least in one of the environments. Genotype G16 performed the best for mean grain yield at seven environments $(\mathrm{E} 1, \mathrm{E} 5, \mathrm{E} 6, \mathrm{E} 7, \mathrm{E} 8, \mathrm{E} 9$, and E10) and it was one of the highest yielding genotypes in both poor and favorable environments (Table 6). The other four high yielding genotypes include G11 which performed best in five environments (E3, E4, E5, E7, and E11), G3 in four environments (E2 and E6, E8 and E10), and (G1, G2 and G5) each in three environments (E2 and E6, E7), (E3, E4, and E11), and (E2, E8, and E10), respectively (Table 6). The switch in ranking of genotypes across different environments demonstrated that the GE interaction effect was a crossover type (Yan and Hunt, 2001; Kang, 2002) in which the genotype selected for high yield under one environmental condition may not always be superior under another environmental condition.

Table 5. Mean performances of 18 lowland rice genotypes for grain yield and yield related traits at five locations over three years

\begin{tabular}{|c|c|c|c|c|c|c|c|c|c|c|}
\hline Genotype & $\begin{array}{c}\text { DTH } \\
\text { (days) }\end{array}$ & $\begin{array}{l}\text { DTM } \\
\text { (days) }\end{array}$ & $\begin{array}{c}\text { PL } \\
(\mathrm{cm})\end{array}$ & $\begin{array}{c}\text { PH } \\
\text { (cm) }\end{array}$ & $\begin{array}{c}\text { FGP } \\
\text { (no) }\end{array}$ & $\begin{array}{l}\text { FR } \\
(\%)\end{array}$ & $\begin{array}{c}\text { TSW } \\
\text { (g) }\end{array}$ & $\underset{\left(\mathrm{kgha}^{-1}\right)}{\mathbf{G y}}$ & $\begin{array}{c}\text { LB } \\
\text { (scale) }\end{array}$ & $\begin{array}{c}\text { BS } \\
\text { (scale) }\end{array}$ \\
\hline G1 & 91 & 122 & 20.0 & 75.6 & 87.3 & 83.0 & 22.7 & 4198.0 & 2.0 & 1.3 \\
\hline G2 & 79 & 117 & 18.0 & 82.8 & 96.1 & 94.5 & 30.7 & 5409.8 & 0.9 & 1.1 \\
\hline G3 & 85 & 119 & 21.4 & 112.6 & 90.5 & 85.4 & 29.0 & 4940.8 & 4.2 & 3.1 \\
\hline G4 & 96 & 125 & 20.6 & 90.0 & 102.5 & 89.2 & 23.7 & 4849.4 & 1.4 & 1.5 \\
\hline G5 & 86 & 119 & 21.6 & 111.5 & 88.1 & 86.0 & 30.3 & 4827.5 & 4.4 & 2.9 \\
\hline G6 & 82 & 118 & 18.0 & 68.3 & 89.4 & 90.8 & 23.7 & 3644.9 & 1.8 & 2.3 \\
\hline G7 & 87 & 120 & 17.7 & 72.0 & 83.1 & 91.4 & 25.1 & 4362.2 & 1.5 & 1.5 \\
\hline G8 & 72 & 115 & 17.5 & 73.1 & 87.8 & 92.3 & 23.8 & 3842.7 & 1.8 & 1.6 \\
\hline G9 & 76 & 116 & 17.2 & 71.5 & 84.1 & 81.8 & 23.7 & 3814.4 & 1.4 & 1.6 \\
\hline G10 & 89 & 121 & 19.0 & 99.0 & 106.4 & 91.5 & 25.5 & 4552.4 & 1.2 & 1.5 \\
\hline G11 & 94 & 124 & 20.3 & 74.6 & 93.1 & 92.8 & 29.6 & 5423.1 & 1.1 & 1.0 \\
\hline G12 & 74 & 115 & 19.3 & 79.1 & 104.7 & 94.0 & 28.3 & 4766.1 & 1.2 & 1.7 \\
\hline G13 & 74 & 115 & 18.4 & 89.0 & 72.7 & 93.0 & 31.4 & 3439.1 & 1.4 & 1.4 \\
\hline G14 & 71 & 110 & 20.4 & 114.4 & 78.8 & 94.0 & 30.4 & 4508.3 & 1.2 & 1.4 \\
\hline G15 & 74 & 116 & 20.5 & 96.5 & 96.6 & 89.0 & 31.3 & 4458.3 & 1.7 & 1.8 \\
\hline G16 & 72 & 115 & 19.6 & 90.0 & 101.1 & 94.0 & 32.8 & 5812.3 & 1.0 & 0.2 \\
\hline G17 & 74 & 114 & 19.3 & 90.1 & 103.0 & 91.6 & 30.2 & 4626.6 & 1.1 & 1.2 \\
\hline G18 & 73 & 112 & 18.8 & 99.3 & 96.8 & 95.1 & 32.8 & 4621.6 & 0.9 & 1.3 \\
\hline Mean & 80 & 117 & 19.30 & 88.29 & 92.34 & 90.52 & 28.02 & 4560.98 & 1.68 & 1.58 \\
\hline CV (\%) & 4.76 & 2.80 & 7.94 & 6.64 & 15.33 & 5.54 & 9.10 & 17.77 & 53.00 & 33.70 \\
\hline $\operatorname{LSD}(5 \%)$ & 1.85 & 1.59 & 0.74 & 2.84 & 6.81 & 2.43 & 1.20 & 392.31 & 0.44 & 0.27 \\
\hline
\end{tabular}

DTH: days to heading, DTM: days to maturity, PL: panicle length, PH: plant height, FGP: number of filled grains per panicle, FR: fertility rate, TSW: thousand seed weight, Gy: grain yield, LB: leaf blast and BS: brown spot.

Table 6. Mean grain yield $\left(\mathrm{kg} \mathrm{ha}^{-1}\right)$ of 18 lowland rice genotypes across even environments during (2013-205) main cropping season

\begin{tabular}{|c|c|c|c|c|c|c|c|c|c|c|c|c|}
\hline \multirow{2}{*}{ Genotype } & \multicolumn{12}{|c|}{ Environments $^{a}$} \\
\hline & E1 & E2 & E3 & E4 & E5 & E6 & E7 & E8 & E9 & E10 & E11 & Mean \\
\hline G1 & 2352 & $\underline{6150}$ & 2982 & 3437 & 3449 & $\underline{4950}$ & $\underline{5179}$ & 4003 & 5622 & 2889 & 5165 & 4198 \\
\hline $\mathrm{G} 2$ & 4494 & $\overline{5263}$ & 7064 & 7747 & 4021 & $\overline{4163}$ & $\overline{4008}$ & 5436 & 5157 & 4327 & 7828 & 5410 \\
\hline G3 & 3225 & 7115 & $\overline{2570}$ & $\overline{5247}$ & 5116 & $\underline{4821}$ & 3923 & $\underline{5529}$ & 4802 & $\underline{5879}$ & $\overline{6123}$ & 4941 \\
\hline G4 & 2406 & 5025 & 6245 & 5483 & 5913 & 3071 & 4896 & 4455 & 5940 & $\overline{5321}$ & 4590 & 4849 \\
\hline G5 & 2800 & 7350 & 2731 & 6751 & 4863 & 4396 & 3559 & $\underline{5519}$ & 4439 & $\underline{5814}$ & 4880 & 4827 \\
\hline G6 & 3726 & $\overline{5352}$ & 2569 & 5743 & 2405 & 3771 & 2477 & $\overline{3907}$ & 3839 & $\overline{2338}$ & 3968 & 3645 \\
\hline G7 & $\underline{4836}$ & 5255 & 3275 & 5869 & 2968 & 4092 & 3117 & 4764 & 4757 & 3088 & 5965 & 4362 \\
\hline G8 & $\overline{4042}$ & 5127 & 3135 & 4870 & 3953 & 3808 & 3200 & 3706 & 3622 & 2713 & 4094 & 3843 \\
\hline G9 & 3756 & 4477 & 2438 & 5192 & 3928 & 4142 & 2436 & 4870 & 4009 & 2379 & 4331 & 3814 \\
\hline G10 & 2468 & 4020 & 4460 & 5053 & 4388 & 4592 & 3691 & 4869 & $\underline{6015}$ & 3972 & $\underline{6550}$ & 4552 \\
\hline G11 & 3639 & 5927 & $\underline{5589}$ & $\underline{6778}$ & $\underline{6955}$ & 4533 & $\underline{4892}$ & 5453 & $\overline{5680}$ & 2716 & $\overline{7493}$ & 5423 \\
\hline G12 & $\underline{5475}$ & 5722 & $\overline{5367}$ & $\overline{6628}$ & $\overline{4428}$ & 4492 & $\overline{3300}$ & 4757 & 4129 & 2221 & $\overline{5909}$ & 4766 \\
\hline G13 & 2836 & 4165 & 2572 & 5258 & 3138 & 3283 & 2687 & 4488 & 2794 & 3101 & 3509 & 3439 \\
\hline G14 & 2961 & 5377 & 5479 & 7085 & 4338 & 4258 & 4311 & 4889 & 2809 & 3528 & 4558 & 4508 \\
\hline
\end{tabular}




\begin{tabular}{|c|c|c|c|c|c|c|c|c|c|c|c|c|}
\hline \multirow{2}{*}{ Genotype } & \multicolumn{12}{|c|}{ Environments $^{a}$} \\
\hline & E1 & E2 & E3 & E4 & E5 & E6 & E7 & E8 & E9 & E10 & E11 & Mean \\
\hline G15 & 3845 & 4510 & 2347 & 6099 & 5075 & 3958 & 3871 & 4533 & $\underline{6055}$ & 3280 & 5468 & 4458 \\
\hline G16 & 6155 & 5567 & 5575 & 5875 & 5756 & 5675 & 5774 & 5819 & 6174 & 5647 & 5918 & 5812 \\
\hline G17 & $\overline{3973}$ & 4995 & 3284 & 5869 & $\overline{5063}$ & $\overline{3917}$ & $\overline{4340}$ & $\overline{4588}$ & $\overline{5288}$ & $\overline{3634}$ & 5944 & 4627 \\
\hline G18 & 4340 & 4123 & 4825 & 5928 & 4520 & 4033 & 3882 & 4584 & 4120 & 4721 & 5761 & 4622 \\
\hline Mean & 3741 & 5307 & 4028 & 5828 & 4460 & 4220 & 3863 & 4787 & 4736 & 3754 & 5447 & 4561 \\
\hline CV $(\%)$ & 29.93 & 16.95 & 19.99 & 14.43 & 19.86 & 14.15 & 11.51 & 14.22 & 15.67 & 21.35 & 12.48 & 17.77 \\
\hline LSD & 1857. & 1492. & 1336. & 1395. & 1469. & 991.0 & 737.9 & 1129. & 1231. & 1329. & 1128. & 392.3 \\
\hline$(0.05)$ & 9 & 7 & 2 & 6 & 3 & 2 & 4 & 1 & 8 & 6 & 9 & 1 \\
\hline
\end{tabular}

${ }^{a}$ E1: Woreta 2013, E2: Maitebri 2013, E3:Jimma 2013, E4: Woreta 2014, E5: Jimma 2014, E6: Maitsebri 2014, E7: Pawe 2014, E8: Woreta 2015, E9: Pawe2015, E10: Jimma 2015, E11: Assosa 2015

\subsection{AMMI stability value (ASV) and yield stability index (YSI)}

Ranking of 18 lowland rice genotypes based on mean grain yield, IPCA 1 score, ASV, and YSI is presented in Table 7. In terms of mean grain yield, genotype G16 ranked first followed by G11, G2, and G3 with 5812, 5423, 5410 and $4941 \mathrm{~kg} \mathrm{ha}^{-1}$, respectively. The IPCA1 scores also demonstrated that G16 was the most stable genotype, followed by G10, G8, and G6, whereas the other high yielding genotypes (G11, G2, and G3) were unstable as they had high IPCA1 scores. ASV stability measure as proposed by Purchase et al. (2000) also stated that genotypes with the least ASV or have the smallest distance from the origin in the biplot are considered as the most stable genotypes, whereas those which have the highest ASV are considered as unstable. Accordingly, G17 was the most stable genotype for grain yield, followed by G16, G8, G13 and G15, as they had the least ASV while G2 was the most unstable genotype, followed by G4, G3, and G5 (Table 7).

Table 7. Ranking of 18 short-duration lowland rice genotypes based on, IPCA1scores, AMMI stability value (ASV), and yield stability index (YSI) mean grain yield ( $\left.\mathrm{Gm}, \mathrm{kgha}^{-1}\right)$ at eleven environments.

\begin{tabular}{lrccccccc}
\hline Genotype & IPCA1 & Rank & ASV & Rank & YSI & Rank & Gm & Rank \\
\hline G1 & 25.947 & 14 & 35.170 & 13 & 27 & 17 & 4198 & 14 \\
G2 & -37.508 & 18 & 46.600 & 18 & 21 & 10 & 5410 & 3 \\
G3 & 36.539 & 17 & 45.321 & 16 & 20 & 8 & 4941 & 4 \\
G4 & -3.854 & 7 & 46.195 & 17 & 22 & 13 & 4849 & 5 \\
G5 & 32.104 & 16 & 40.512 & 15 & 21 & 11 & 4827 & 6 \\
G6 & 2.52 & 4 & 26.441 & 12 & 29 & 18 & 3645 & 17 \\
G7 & -3.728 & 6 & 22.465 & 9 & 22 & 14 & 4362 & 13 \\
G8 & 2.028 & 3 & 11.744 & 3 & 18 & 6 & 3843 & 15 \\
G9 & 4.175 & 9 & 17.927 & 7 & 23 & 16 & 3814 & 16 \\
G10 & -1.952 & 2 & 24.324 & 10 & 20 & 9 & 4552 & 10 \\
G11 & -16.511 & 12 & 25.915 & 11 & 13 & 3 & 5423 & 2 \\
G12 & -27.159 & 15 & 40.082 & 14 & 21 & 12 & 4766 & 7 \\
G13 & 3.559 & 5 & 12.171 & 4 & 22 & 15 & 3439 & 18 \\
G14 & -17.596 & 13 & 21.885 & 8 & 19 & 7 & 4508 & 11 \\
G15 & 9.958 & 10 & 12.415 & 5 & 17 & 5 & 4458 & 12 \\
G16 & 0.39 & 1 & 6.375 & 2 & 3 & 1 & 5812 & 1 \\
G17 & 3.976 & 8 & 6.190 & 1 & 9 & 2 & 4627 & 8 \\
G18 & -12.889 & 11 & 16.733 & 6 & 15 & 4 & 4622 & 9 \\
\hline
\end{tabular}

The YSI estimate which combined mean yield and ASV rankings elucidated that G16 was the most stable genotype followed by G17, G11, and G18, because they had the least YSI. On the other hand, G1, G6 and G9 were the most unstable genotypes as they showed the highest YSI. Genotype G16 was the best genotype as it ranked first in mean yield, IPCA1 score YSI and, second in ASV. However, genotypes G11 and G2 which ranked second and third in mean yield showed inconsistency in stability ranking and, thus both were unstable. Inconsistency in the ranking of genotypes based on different approaches demonstrated the importance of considering both mean yield and stability performance to guide selection of genotypes in the breeding program (Farshadfar et al., 2011).

\subsection{AMMI and GGE biplots}

AMMI biplots, AMMI1 (IPCA1 vs mean yield) and AMMI2 (IPCA1 vs IPCA2) were applied to further illustrate the effect of each genotype, environment and the interaction in the multi-environment data as presented in Figure 1 and Figure 2, respectively. In AMMI1 biplot, genotypes or environments laid on the same vertical line had similar mean yields and those laid on the same horizontal lines had similar interaction patterns (Crossa et al., 1990). In addition, a genotype or an environment plotted on the right side of the central vertical axis had 
higher yield than those of left hand side and, if a genotype or an environment has IPCA1 score of nearly zero, it has less interaction effect (Zobel et al., 1988). Accordingly, genotypes G2, G3, G4, G5, G10, G11, G12, G16, G17, and G18 exhibited above average in mean yield. Of the three best yielding genotypes (G16, G2, and G11), G16 had the lowest IPCA1 score suggesting its wider adaptation and can be cultivated across tested environments while G2 and G11 had relatively large IPCA1 scores and thus unstable; that is, they had specific adaptations. In contrast, genotypes G1, G6, G8, G9, and G13 performed bellow average in mean yield with lower IPCA1 scores except for G1 which had larger IPCA1 score and then highly interactive (Figure 1).

With regard to environments, the highest yielding environment was E4, followed by E11 and E2, all with large IPCA1 scores indicating their strong contribution to the interaction effect. In contrast, E1, E3, E6 and E7 were low yielding with large IPCA1 scores except for E6 and E7 that had relatively smaller IPCA1 scores. On the other hand, E5, E8 and E9 were average yielding environments and closer to the biplot origin suggesting their smaller contribution to the interaction (Figure 1).

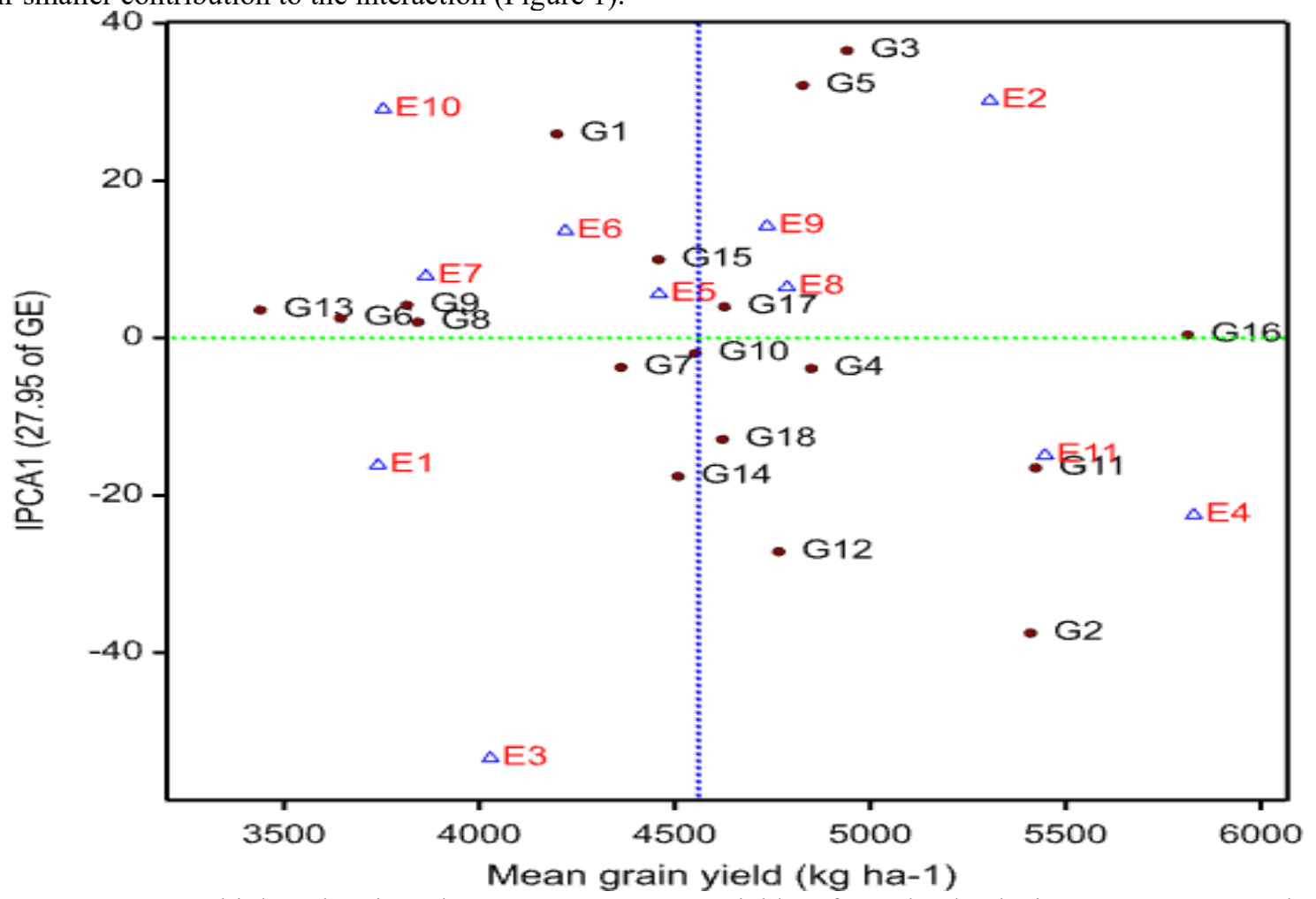

Figure 1. AMMI1 biplot showing the IPCA1 vs mean yields of 18 lowland rice genotypes at eleven environments. E1: Woreta 2013, E2: Maitebri 2013, E3: Jimma 2013, E4: Woreta 2014, E5: Jimma 2014, E6: Maitsebri 2014, E7: Pawe 2014, E8: Woreta 2015, E9: Pawe2015, E10: Jimma 2015, E11: Assosa 2015. Genotypes codes are presented in Table 1.

In AMMI2 biplot, environments positioned far from the biplot origin had large contribution to the GE interaction and if they are closer to the origin, they contributed for the stability of genotypes. Similarly, genotypes close to the biplot origin are stable while those distant are unstable and genotypes and environments positioned close to each other in the biplot have positive associations (Silivera et al., 2012). Accordingly, significant GE interaction was attributed to E1, E2 and E3 as they were away from the biplot origin. In contrast, E6, E8 and E11 contributed the lowest to the GE interaction and thus most stable while the other environments (E4, E5, E7, E9 and E10) were intermediate (Figure 2). Genotypes G15, G16, and G18 were close to the biplot origin which suggested that they were relatively stable, G16 being the most stable and this was also in accordance with Figure 1. Located far away the biplot origin, genotypes G1, G2, G3, G5, and G12 were the most unstable and associated to different environments (Figure 2).

GGE biplot analysis is also a data visualizing tool used for, among other things, evaluating cultivars based on average yield and stability performance, identifying best cultivar in each environment and grouping environments based on cultivars performance (Yan, 2001; Yan et al., 2007). In this study, the GGE biplots in Figures 3 and 4 each explained 59.11\% of the total variation in grain yield of 18 rice genotypes, with the first and second principal component (PC1 and $\mathrm{PC} 2$ ) contributing $41.78 \%$ and $17.33 \%$ of the variations, respectively. Figure 3 demonstrates the ranking of 18 rice genotypes based on both mean grain yield and stability performance. Genotypes in the direction of the arrow or on the positive side of the vertical solid line are high yielding while those on negative side are with low mean yield (Yan, 2001). Moreover, genotypes with short vectors, regardless 
of their directions, are more stable whereas with longer vectors are unstable (Yan and Tinker, 2006). In the present study, the best performing genotypes in terms of mean yield were G16, G11, G2 and G4 while poor performing genotypes were G13, G6, G9, G8, G7 and G1 as illustrated in Figure 3. With regard to stability of genotypes as dictated by the length of genotype vectors in either direction, G16, G13, G9 and G8 could be considered as the most stable genotypes. However, the latter three genotypes were poor in terms of mean yield performance. Genotypes G11 and G2 were also the highest in mean yield, G11 being relatively stable while G2 was unstable. Thus, genotype G16 followed by G11 was the highest yielding genotypes and consequently, G16 is the most ideal genotype for rain fed lowland rice cultivation in all environments due to high mean yield and high yield stability while G11 can be recommended for specific environments.

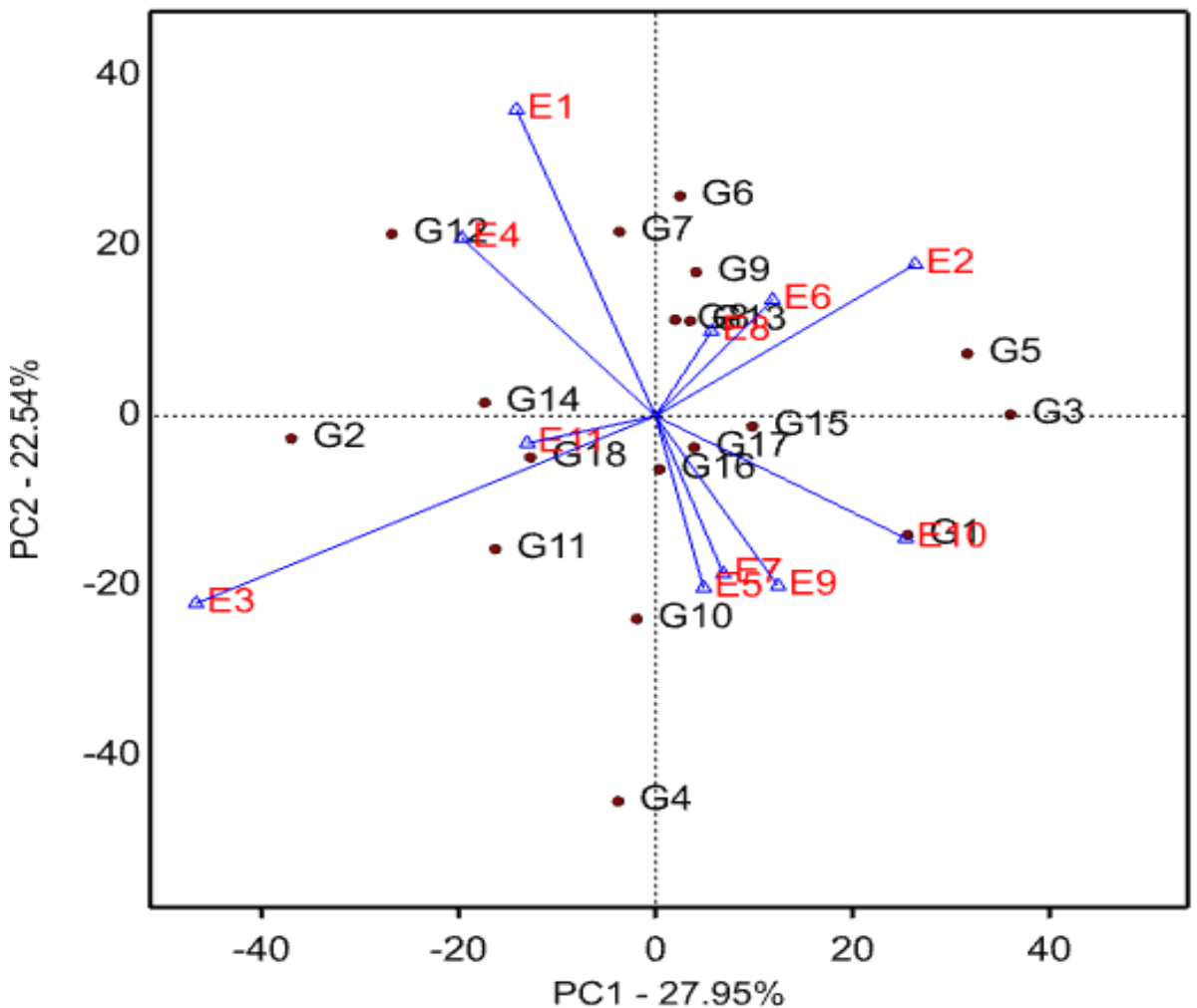

Figure 2. AMMI2 biplot showing the first two principal axes of interaction (IPCA1 vs IPCA2) for grain yield of 18 lowland rice genotypes at eleven environments. E1: Woreta 2013, E2: Maitebri 2013, E3: Jimma 2013, E4: Woreta 2014, E5: Jimma 2014, E6: Maitsebri 2014, E7: Pawe 2014, E8: Woreta 2015, E9: Pawe2015, E10: Jimma 2015, E11: Assosa 2015. Genotypes codes are presented in Table 1.

Another most attractive feature of a GGE biplot is its ability to show the 'which-won-where' pattern in a genotype-by-environment dataset, as it graphically demonstrates relationships of genotypes to different environments (Yan and Tinker, 2006). Genotypes located on the vertices of the polygon performed either the best or the poorest in one or more environments. Accordingly, genotypes G16, G11, G4, and G10 were better in the environments E9, E8, E7, and E5, where as the genotypes G2, G12, G14, and G18 were better in the environments E1, E3, E4, and E11 (Figure 4). 


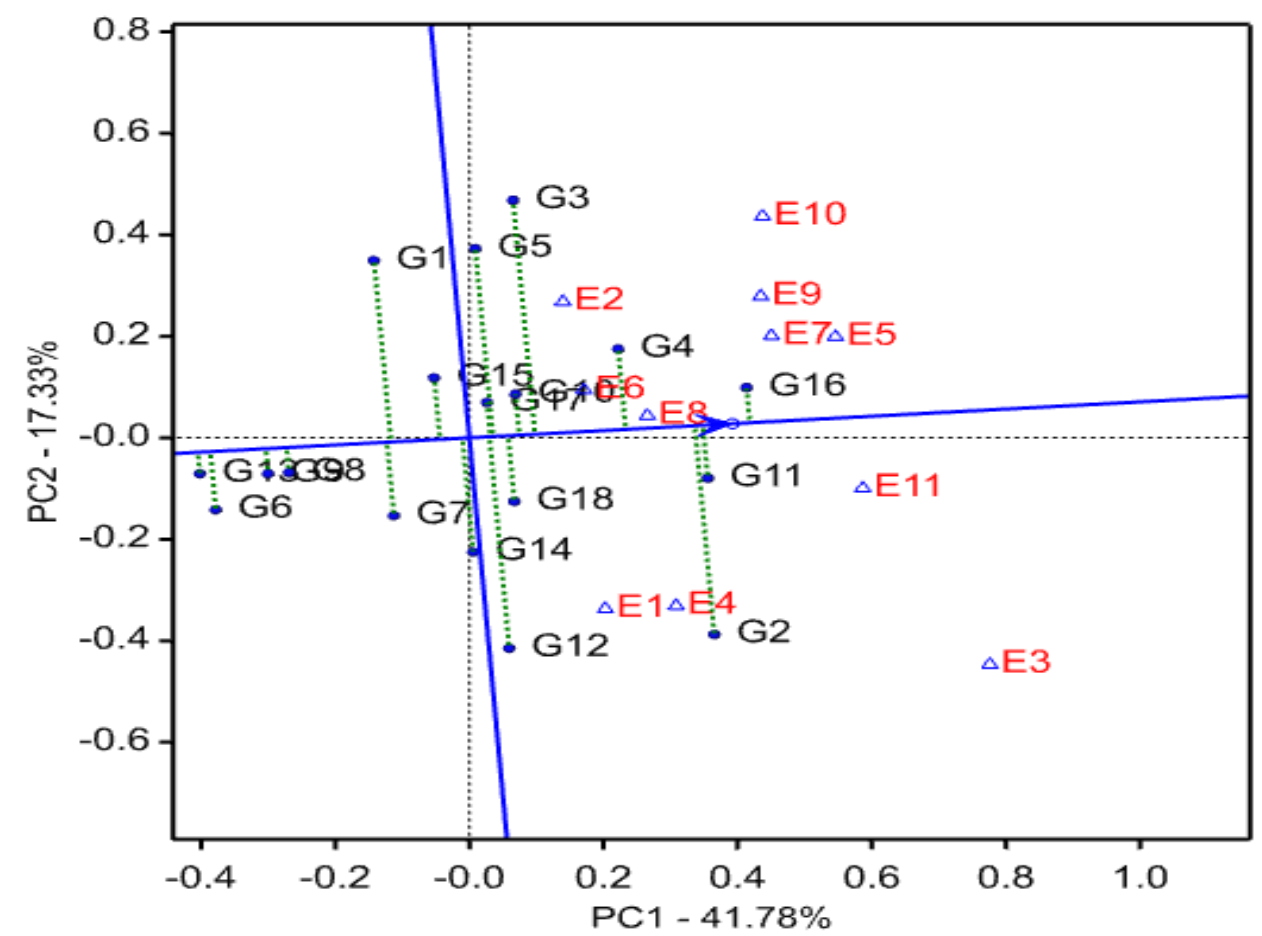

Figure 3. GGE biplot showing ranking of 18 genotypes based on stability and mean performance at 11 environments. E1: Woreta 2013, E2: Maitebri 2013, E3: Jimma 2013, E4: Woreta 2014, E5: Jimma 2014, E6: Maitsebri 2014, E7: Pawe 2014, E8: Woreta 2015, E9: Pawe2015, E10: Jimma 2015, E11: Assosa 2015. Genotypes codes are presented in Table 1.

Genotypes G3, and G5 also performed better in environments E2 and E10 while G1, G6, G7, G8, G9, G13 and G15 did not perform well in any of the environments. This biplot suggested the presence of three megaenvironments where genotypes G2, G3 and G16 as winner genotypes at each group of environments, whereas genotypes G1, G6, G13 though identified as vertex genotypes but they were not associated to any environments indicating as they were not best at least in one environment (Figure 4).

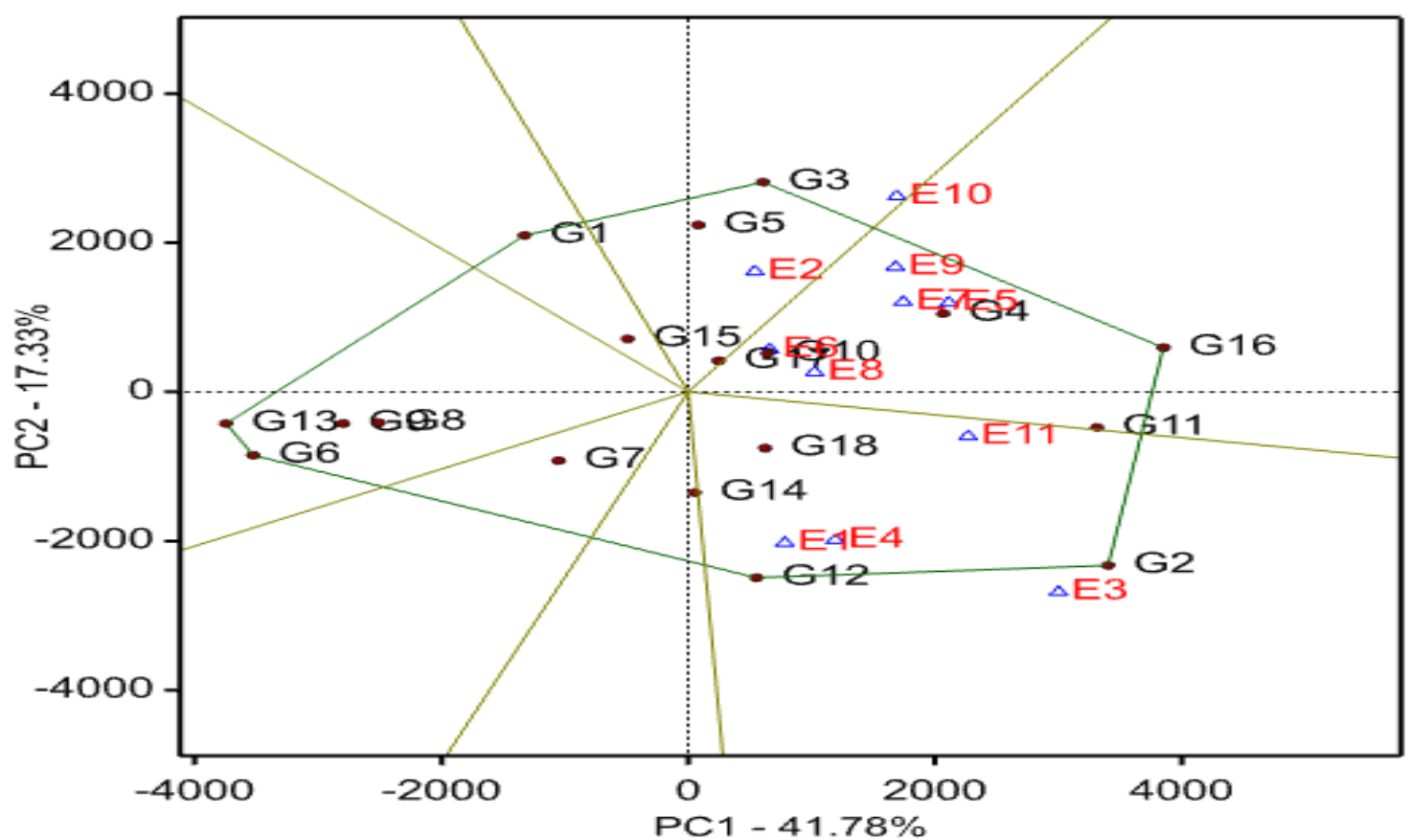

Figure 4. GGE biplot showing winner genotypes at specific environments. E1: Woreta 2013, E2: Maitebri 2013, E3:Jimma 2013, E4: Woreta 2014, E5: Jimma 2014, E6: Maitsebri 2014, E7: Pawe 2014, E8: Woreta 2015, E9: Pawe2015, E10: Jimma 2015, E11: Assosa 2015. Genotypes codes are presented in Table 1. 


\section{Conclusion and recommendation}

The study of genotype $\mathrm{x}$ environment (GE) interaction is critical for appropriate genotype evaluation in multienvironment trials. Genotypes that showed both high mean yield performance and stability across a wide range of environmental conditions are desirable for rice production. However, the presence of GE interaction makes difficult which genotypes to select. In the current study, results indicated that the yield performance of rice genotypes was significantly influenced by GE interaction effects which contributed nearly two times higher than genotype effects. The GGE biplots and AMMI were also used to compare the performance of different genotypes across test environments. Genotypes G16, G11 and G2 were identified as the top three high yielding genotypes. Genotype, G16 was the highest yielding and most stable genotype, followed by G11 as shown by AMMI stability value, yield stability index, and GGE ranking biplot, while the remaining tested genotypes showed inconsistent performances across environments. Thus, considering the grain yield performance and stability of genotypes, G16 and G11 could be recommended for wider adaptation while G2 for specific adaptation.

\section{Acknowledgements}

The financial support of Ethiopian Institute of Agricultural Research (EIAR) is highly acknowledged. Rice research team members at Fogera, Pawe, Maitsebri, Jimma and Assosa research centers are appreciated for their cooperation in this study.

\section{References}

Africa Rice Center (AfricaRice) (2017) Annual Report 2016: Towards rice self-sufficiency in Africa. Abidjan, Côte d'Ivoire, p. 36.

Bose LK, Jambhulkar NN, Pande K, Singh ON (2014). Use of AMMI and other stability statistics in the simultaneous selection of rice genotypes for yield and stability under direct-seeded conditions. Chilean J. Agric. Res. 74(1):1-9.

Cantila AY, Abdula SE, Imbat JB, Quitel AJR (2020). Additive main effect and multiplicative interaction (AMMI) stability analysis for grain yield of 27 rice genotypes tested in six environments. Philipp. Sci. Lett.13 (1): 6-12.

Crossa J, Gauch HG, Zobel RW (1990). Additive Main Effects and Multip-A. Seyoum et al. licative Interaction Analysis of Two International Maize Cultivar Trials. Crop Sci. 30: 493-500.

Eisemann RL, Cooper M, Woodruff DR (1990). Beyond the analytical methodology, better interpretation and exploitation of GE interaction in plant breeding, pp. 108-117. In: Genotype-by-environment interaction and plant breeding, (ed.) Kang MS, Louisiana State Univ. Agric. Center, Baton Rouge, LA.

Farshadfar E, Farshadfar M, Sutka J (2000). Combining ability analysis of drought tolerance in wheat over different water regimes. Acta Agron Hung. 48(4):353-361.

FAOSTAT (2020). Food and Agriculture Organization of the United Nations (FAO). www.fao.org/faostat/en/\#data.

Farshadfar E, Mahmodi N, Yaghotipoor Y (2011). AMMI stability value and simultaneous estimation of yield and yield stability in bread wheat (Triticum aestivum L.). AJCS5 (13):1837-1844.

Gauch HG, Zobel RW (1988). Predictive and postdictive success of statistical analyses of yield trials. Theor. Appl. Genet. 76:1-10.

Gauch HG (2006). Statistical Analysis of Yield Trials by AMMI and GGE. Crop and Soil Sciences, Cornell University, 519 Bradfield Hall, Ithaca, NY, 14853.

Gauch HG (1988). Model selection and validation for yield trials with interaction. Biometrics. 44: 705-715.

Hasan MJ, Kulsum MU, Hossain MM, Akond Z, Rahman MM (2014). Identification of stable and adaptable hybrid rice genotypes. SAARC J. Agri.. 12(2):1-15.

IRRI (1996). Standard Evaluation System for Rrice. Rice knowledge Bank.IRRI, Philippines.

Kang MS (2002). Genotype-Environment Interaction Progress and Prospects: In: Kang MS (ed) 2002. Quantitative Genetics, Genomics and Plant Breeding. CAB International, pp: 221-243.

Lakew T, Tanaka K, Ishikawa R (2021). Genetic diversity of African wild rice (Oryza longistaminata Chev. et Roehr) at the edge of its distribution. Genet Resour Crop Evol, https://doi.org/10.1007/s10722-020-01080-6.

Maclean JL, Dawe DC, Hardy B, and GP Hettel (eds) (2002). Rice Almanac: Source Book for the Most Important. CABI publishing, UK, London.

Ogunbayo et al. (2014). Comparative performance of forty-eight rice genotypes in diverse environments using AMMI and GGE biplot analysis. Int. J. Plant Breed. Genet. 8(3): 139-152.

Purchase JL, Hatting H, van Deventer CS (2000). Genotype x environment interaction of wheat in South Africa: stability analysis of yield performance. S. Afr. 1. Plant Soil. 17(3): 101-107.

SAS Institute Inc. 2002. Version 9.0. SAS Institute Inc., Cary, NC.

Silveira LC, Kist V, Paula T, Barbosa MHP, Peternelli LA, Daros E (2012). AMMI analysis to evaluate the 
adaptability and phenotypic stability of sugarcane genotypes. Sci. Agric. 70 (1):27-32.

Taddesse L, Abebae D, Sewagen T, Desta A (2017). Evaluation of Performance and Yield Stability Analysis Based on AMMI and GGE Models in Introduced Upland Rice Genotypes. IJRSAS. 3(2):17-24.

Tadesse T, Dechassa N, Bayu W, Gebeyehu S (2013). Mitigation of Terminal Moisture Stress for Rain-fed Lowland Rice Production in Fogera Plain, North-western Ethiopia. PhD thesis. Haramaya University, Haramaya, Ethiopia.

Takahashi N (1984). Differentiation of ecotypes in Oryza sativa L. In: Takahashi N and Tsunoda S. (Ed.) Biology of rice. Tokyo: Japanese Scientific Society. pp.31-67.

Tumuhimbise R, Melis R, Shanahan P, Kawuki R (2014). Genotype x environment interaction effects on early fresh storage root yield and related traits in cassava. The Crop Journal. 2(5): 329-337.

Yan W (2001). GGEbiplot a Windows application for graphical analysis of multi-environment trial data and other types of two-way data. Agron. J. 93(5):1111-1118.

Yan W, Hunt LA (2001). Interpretation of genotype $x$ envornment interactions: An Empirical Comparision Agron. J. 87:121-126.

Yan W, Hunt LA, Sheng Q, Szlavnics Z (2000). Cultivar evaluation and mega-environment investigation based on the GGE biplot. Crop Sci. 40(3):597-605.

Yan W, Kang MS (2003). GGE-biplot Analysis: A graphical tool for breeders, geneticists, and agronomists. CRS press, Boca Raton, FL.

Yan W, Kang MS, Baoluo M, Woods S, Cornelius PL (2007). GGE biplot vs AMMI analysis of genotype-byenvironment data. Crop Sci. 47: 643-655.

Yan W, Rajcan I(2002). Biplot analysis of test sites and trait relations of soybean in Ontario. Crop Sci. 42:11-20.

Yan W, Tinker NA (2006). Biplot analysis of multi-environment trial data: Principles and applications. Canadian Journal of Plant Science 86: 626-645.

Zobel RW, Wright MJ, Gauch HG(1988). Statistical analysis of a yield trial. Agronomy Journal 80:388-393. 